\title{
Managing Service Quality of High School Delivery: Evidence from Kuwait
}

\author{
A. I AL-Refai ${ }^{1}$, H. O. Al-Omar ${ }^{1}$, M. S. Son ${ }^{1, *} \&$ H. I. Hamdy ${ }^{1}$ \\ ${ }^{1}$ Kuwait University and University of Vermont, USA \\ *Corresponding author: Kuwait University and University of Vermont, USA. E-mail: \\ mathsec@uvm.edu
}

Received: June 23, 2014 Accepted: March 23, 2015 Published: April 16, 2015

doi:10.5296/ije.v7i2.5803 URL: http://dx.doi.org/10.5296/ije.v7i2.5803

\begin{abstract}
This paper details a survey study designed and administered to test a Deming-like TQM model for public high schools in Kuwait. Structural equation modeling was used to fit the data to the proposed model according to well-known procedures and criteria. This study adds value to the TQM-in-education literature in that it investigates the applicability of Anderson's et al. (1994) quality model in public education in a culture outside of the United States of America. Because of the nature of educational systems, we suggest an additional construct (School Assured Satisfaction) before the final construct (Customer Satisfaction). The study also investigates the total impact that each element has on both School Assured, and Customer Satisfaction based on the stakeholders' opinion. In addition, this paper recommends implementing an active measurement system to help secondary schools implement TQM correctly. Such a system acts as a "quality assurance system" in which leading measurements are taken periodically throughout the school year to increase the chances of achieving the lagging measurements associated with assuring both quality education and customer satisfaction.
\end{abstract}

Keywords: Anderson et al. Deming Management Model, Confirmatory Factor Analysis, Deming Model for TQM, Endogenous Variables, Exogenous Variables, Exploratory Factor Analysis, Moderating Variables, Path Analysis, Structure Equation Modeling, Survey Design and Analysis, TQM in Education. 


\section{Introduction}

The United Nations Educational, Scientific and Cultural Organization (UNESCO), known as the "intellectual" agency of the United Nations, was founded in 1945. Its aim is to "contribute to the building of peace, the elimination of poverty, sustainable development and intercultural dialogue through education, the sciences, culture, communication, and information" (UNESCO). One of the objectives of UNESCO is fulfilling the fundamental human right to receive a quality education that promotes lifelong learning and leads to human development. To operationalize "quality education" for the twenty-first century, UNESCO published a report in 1993 entitled: Learning: The Treasure Within (Delors, et al., 1996). This report, known as the Delors Report, has become a key guide for education and learning reforms worldwide. It proposes a vision of lifelong learning, emphasizing that learning is about developing the whole person, enabling each person to reach their full potential. People engaged in this process are better able to play an active role in leading a fulfilling life and building a unified society, (Bertelsmann, 2010). The vision is based on four pillars: learning to know (learning to learn), learning to do (vocational and teamwork skills), learning to be (development of one's potential to its fullest), and learning to live together (understanding others; Tawil and Cougoureux, 2013).

Kuwait's concern for quality education led to their membership in UNESCO in 1979, and the establishment of the Kuwait National Commission for Education, Science, and Culture. This commission acts as a liaison between the UNESCO and the State of Kuwait. Its prime objective is to help raise the level of education, science, and culture in Kuwait, and to contribute to the global community. Kuwait has always supported and invested resources on education. In 2012, $8.3 \%$ of Kuwait's GDP was devoted to public education (K-12; Al-Ghunaim, 2013).

Since the first official school was opened in 1911, Kuwait has been dedicated to the delivery and improvement of quality public education. By 1936, the growing number of schools in Kuwait prompted the establishment of the Education Council to organize, finance, and improve the quality of education. Through the council's efforts, two major quality improvements were made: recruitment and hiring of teachers from other Arab countries, and, in 1941, the granting of scholarships to Kuwaiti students (male and female) to pursue their university education abroad, with the condition of returning to teach in the public schools. After Kuwait gained independence and formed a government, the council became the Ministry of Education (MOE) in 1962. During the tenure of the second appointed minister of education (1964 - 1967) the relationship between schools and parents was strengthened by establishing a Parents Council in each school. The objective was to encourage two-way communication with the community and to improve the quality of education, enhancing stakeholder satisfaction. Between 1967 and 2001, ten ministers lead the MOE, each working diligently to improve the quality of public education in Kuwait schools based on goals and vision appropriate for the time. During the tenure of the thirteenth appointed minister of education $(2001-2004)$, Kuwait's Strategy for Developing Education (2005 - 2025) was developed. This document was intended to improve the quality of public education by providing strategic guidelines for anticipating and managing existing and future concerns, challenges and issues facing Kuwait's educational system in the $21^{\text {st }}$ century. The strategy emphasized: building an ambitious 
Kuwaiti national; responding to change while preserving national identity and culture; providing democracy and respecting human rights; sustainability of the environment and preservation of the country's resources; updating the curricular to ensure the state's objectives and principles; incorporating advances in Information \& Communication Technology (ICT) in the education process. It is worth noting that the strategic document did not advise the MOE to undertake any sort of operational framework such as ISO, Six Sigma, Total Quality Management (TQM), etc., in attempting to achieve the ambitious strategic goals. Fulfillment of the strategy was left up to the judgment of appointed ministers.

In 2009 the MOE initiated a large TQM project. The project was a result of the 2008 National Conference on Educational Development which recommended the reform of pre-university public school education using TQM principles. The project was initiated by forming The Quality Committee within the MOE. Their duty is to assure that schools are administered using TQM principles in order to achieve quality education that supports both the Strategic Plan for Education $(2005$ - 2025) and the achievement of Kuwait's vision of becoming a regional financial and trade hub by 2035. In January 2010, the First Conference for Total Quality Public Education in Kuwait was held. The purpose of this conference was to spread awareness of current international best practices using TQM in public education and to devise a plan of action for the implementation of TQM in Kuwaiti public schools. The Second Conference for Total Quality Public Education in Kuwait was held in January 2012 and continued the task by reviewing progress since the first conference, disseminating information on global advances and successful practices in curriculum development, and reinforcing the importance of TQM in public education. In March of 2014, a third conference on TQM in education was held with the goal of increasing awareness of current international best practices in quality school administration and how to both measure and improve it.

The MOE's commitment to TQM, the focus in TQM on measurement, and a lack of scholarly research on TQM in schools in Kuwait led us to conduct our study on TQM in public secondary schools (high schools). An extensive literature review conducted on applying TQM in public school education in Kuwait found no results outside of working papers delivered at the aforementioned TQM conferences. The working papers of these conferences included general informative topics covering: success stories of TQM implementation in other countries; TQM in education, its benefits, its implementation, and challenges; criteria and indicators for measuring total quality in public schools; public school accreditation; the role of the school culture, physical environment, teachers, curriculum, technology, and administration to achieve quality education. While these theoretical papers are of value in guiding the implementation of TQM, our intent was to investigate the degree to which Deming's TQM concepts, based on the Anderson et al., (1994) model, were being applied in the field as reflected by principals, staff, teachers, and parents. We wanted to determine if these stakeholders' opinions of the TQM model would translate to TQM implementation in public secondary schools. We also wanted to understand the nature of the total effect (strength levels) that the model constructs had on both delivering assured quality education and achieving customer satisfaction. We believe that these findings, and their implications could be of value to the MOE TQM team's efforts. 
This study investigates the inter-relationships between the entities that lead to quality education in Kuwaiti public high schools as represented by the TQM model (Anderson et al., 1994). The resulting picture reveals the extent to which the model is applicable to public high school education in a culture outside of the United States, and helps shed light on the relative strength (or weakness) of relationships between the model entities. This latter benefit reflects the need to concentrate on the things that need corrective action, rather than expending additional resources on things that are currently working in the schools. In order to achieve this added value, a survey study was designed and a structured questionnaire was devised with a set of instruments representing the seven constructs of the Anderson et. al. (1994) model. Also included are the instruments for the additional construct we propose be added when the original model is used in education. The questionnaires were distributed to a total of 2000 respondents. SPSS and LISREL were used to conduct path analysis, assessing fit and validating the proposed model.

Because of the importance of secondary school in the transition from childhood to adulthood, we chose to focus our study on high school education (grades 10, 11, and 12 in Kuwait) as opposed to kindergarten, elementary, or intermediate school. High school education prepares the student for higher education and/or the working world. Students begin to develop their own attitudes and beliefs toward the self, life, happiness, family, society, work, success, and many other aspects of adult life that together determine the degree of success school education by referring to it as the "crossroads of life," representing the beginning of adulthood. they will experience later on in life. The Delors Report emphasizes the importance of high school education by referring to it as the "crossroads of life," representing the beginning of adulthood.

This paper is organized as follows: Section 2 explains what we mean by both quality and TQM in service organizations in general and specifically in high school education; Section 3 defines the constructs of the proposed model; Section 4 presents the model, research hypotheses, survey design and data collection, and sample characteristics; Section 5 discusses in detail the analysis of data; Section 6 closes the study with our findings and conclusion.

\section{Quality, Tqm and High School Education}

\subsection{Service Quality}

The focus of this paper is on quality in service oriented organizations, namely, in public high schools. Service quality is defined in many ways. In this paper, we define the output, or outcome, quality for service-oriented organizations as the ability of the organization to consistently offer goods and services (i.e., products), and to operate a system for delivering them, that meets or exceeds customer expectations. That is, a customer will perceive a product and the process undertaken to purchase it to be of acceptable or outstanding quality if the actual purchasing experience and the ability of the product to fulfill the customer's demands meet or exceed the expectations held prior to the purchase (Goetsch \& Davis, 1994; Hitt et al., 2005). 


\subsection{Quality in High School Education}

A quality high school education transforms the students' knowledge base, ability, wisdom, and character in a way that prepares them academically for higher education and also shapes them personally to become responsible and contributing members of society.

When thinking about the quality of high school education, it is important to remember that a school is a different kind of service-oriented organization, one that demands high response from the direct customer (i.e., the student), to achieve the goal of quality learning. Tribus (1992) points out that a high school is not a factory and therefore it cannot be lead like a factory. The student is not the product; educating the student is the product of a high school. Tribus suggests that education should be focused on giving each student opportunities to grow in four areas: Knowledge (ability to understand), Know how (ability to do), Wisdom (ability to set priorities), and Character (ability to cooperate, to persevere and to become respected and trusted members of society). Note that these areas are closely related to the four pillars of the Delors Report. The student in this context is the direct customer because he or she must live with the outcomes of the educational process for the rest of his or her life (Tribus, 1992). Additionally, the student must co-manage the learning process in partnership with the educators, and therefore plays a second important role, that of a worker. The student in this model is not passive and must participate actively if the product (educating the student) is to meet high quality standards. Thus the situation is unique in that the customer (the student) can influence the quality of the product depending on their effort and cooperation. In addition to the students, there are other customers of secondary education institutions. Parents, colleges and universities, employers, the government, society in general, and school employees all have a stake and an influence in the successful delivery of the product.

Certainly from the perspective of the institutions and industries that require them, students are a product of secondary education. The unique aspect of education-as-product is its dependence on the student for a large part of its efficacy. To further illustrate this point, note that in manufacturing, the quality of the product can be achieved consistently if the process has been designed and is operated correctly. In return, customer satisfaction can be guaranteed as long as the product meets or exceeds the needs, wants, and expectations of the consumer. However, even when designed to meet stakeholder expectations, an education system relies on each individual student as an integral element in product quality. Students who lack motivation, interest, or who are not ready to learn, who expect high grades without effort, who lack social support from family, peers, and society can negatively impact even the most well-designed education system. The school, therefore must control what it can: designing and operating a quality education system (the school's product), and recognize that important but highly variable elements are often beyond its control. Even in the best high schools, not every student will achieve straight A's, nor can stakeholder satisfaction be $100 \%$. The goal is to embrace continuous improvement through a system based on students' knowledge, know how, wisdom, and character, the basis on which high school quality education is defined. 


\subsection{TQM in Service-Oriented Organizations}

The ability of an organization to produce quality goods and services is a result of establishing and implementing a system that guarantees quality. Organizations differ in the specific quality-producing system they employ based on variables like leadership style and attitude towards quality. The reader will recognize the most popular quality systems adopted: ISO, TQM, Six Sigma, and the use of Balance Score Cards. The focus of this paper is TQM as it applies to public high school education in the State of Kuwait.

For our purposes, TQM is defined as a philosophy of management that involves everyone in the organization and its supply chain partners (from initial suppliers to final distributors) in an integrated effort to generally do four things: 1) design and achieve quality in all that is done and produced, 2) to continuously improve performance at all levels, 3) to achieve customer satisfaction by meeting or exceeding expectations, and 4) to maintain a competitive advantage in the market.

\subsection{TQM in High School Education}

Total Quality Management philosophy is generally attributed to Dr. W. Edwards Deming. Although originally developed to enhance manufacturing performance, for over two decades TQM has been applied to a variety of service organizations such as educational institutions, hospitals, insurance companies, travel agencies, banks, and government institutions. The development of TQM has benefited from work in two separate fields: academic research, and business and industry experience. Research works to extend the applications of TQM to diverse disciplines and to refine and improve the TQM model by incorporating new concepts. Business and industry experience and best practices also refine and optimize TQM concepts, for example by establishing feedback systems to measure quality of specific products or services, and concentrating on the practical, real world concerns businesses encounter.

In the field of education, many ideas of quality management were applied in education over 70 years ago. However, Tribus (1993) dates the first official application of TQM in education to 1988 at Mt. Edgecombe High school in Sitka, Alaska. In detailing Mt. Edgecombe's pioneering application, Tribus states that "when the practical applications of quality management in education are examined closely, it will be found that many ideas put forward by educators as long as 50 years ago, and neglected by contemporary practitioners, were right all along" (1990).

Since Mt. Edgecombe, applying TQM to education has been on an upward trend. Many journals have published articles on efforts to introduce TQM into schools and many books have been written on this subject as well. The American Association of School Administrators (AASA), a professional organization for educational leaders in the United States, established a network of people interested in TQM in education and its application (Tribus, 1992). Pineda (2013) suggested that schools interested in TQM philosophy should build a system based on four pillars: 1) suppliers and customers, 2) continuous improvement, 3) viewing the organization as a system of on-going processes run by people, and 4) a total quality organizational environment. 
Deming's original ideas (e.g., 14-points for managers and his Deadly Diseases of Management; IBS America, Inc. 2012) were summarized and expanded in The Deming Management Method (Walton, 1986) to help managers at all levels and in organizations of all sizes to improve profits and productivity. Anderson et al., (1994) formulated a model (The Deming Management Model) that embraces the TQM philosophy expressed in a The Deming Management Method. The model consists of seven constructs: 1) Visionary Leadership, 2) Internal and External Cooperation, 3) Organizational Learning, 4) Process Management, 5) Continuous Improvement, 6) Employee Fulfillment, and 7) Customer Satisfaction. According to Khan (2006),

These constructs are based on the works of Deming, other researchers and quality experts, and comprehensive reading of quality related literature. Using a Delphi study, academicians and practitioners explored the concepts that are fundamental to Deming's 14 points. As a result of extensive research, these concepts were clustered into seven constructs that express the contents of The Deming Management Method. Anderson et al., (1994) compared each construct with existing management literature to lend credibility to the seven constructs in the Model.

Anderson et al., (1994) emphasized the need to undertake vigorous testing of the theory to confirm its generalizability, and applicability across sectors, countries, industries, employee groups, and time periods. Anderson et al., (1995) empirically validated The Deming Management Method. Subsequently this was used in empirical studies (Rungtusanatham et al., 1998; Fisher et al., 2005; Douglas \& Frendendall, 2004; Singh et al., 2007). The results illustrated strong support for all hypotheses of The Deming Management Method. Other researchers have encouraged further testing efforts of the method in different contexts in order to gain additional knowledge and a deeper understanding that might lead to further conclusions of significance (Rungtusanatham et al., 1998; Sousa and Voss 2002; Fisher et al., 2005).

In this paper, we test The Deming Management Model in public high school education in the State of Kuwait. The proposed model used in this study is a slight modification of the Anderson et al., (1994) model. It reflects what we believe to be a good representation of the way Kuwaiti culture influences the administration of Kuwaiti public high schools. Before introducing the proposed model, a brief definition of what we mean by each construct (exogenous variables, moderator variables, and outcomes) is given next. A complete list of the instruments used to measure these constructs is presented in Table (1), Section 5.1.

\section{Constructs Defined}

\subsection{Exogenous Variables}

\subsubsection{Visionary leadership}

A leader is one who anticipates the need for organizational change and is in a position to proactively achieve change together with other people who are inspired to fulfill the goal as a 
team. A leader is one who empowers an organization to move forward to more growth and excellence by designing its future through an inspiring, worthwhile, challenging, but achievable, vision and then makes it happen with people who are excited, energized, and committed to fulfilling it together (Lavinsky, 2013; Nanus, 1992).

Since the product of a quality high school education can only be determined following graduation, it is crucial for principals, the administrative team, and all stakeholders to be careful and wise when designing the school's future together (Morse, 1992; Bush \& Glover, 2003). It is the vision of that future that determines what is included to develop each of the four areas of learning (i.e., knowledge, know-how, wisdom, and character). What is included will either equip the students with capabilities to deal effectively with the anticipated future they will experience in the university or on the job or it will fail to do so.

\subsection{Moderator Variables}

\subsubsection{Internal \& External Cooperation}

\subsubsection{Internal Cooperation}

Internal cooperation is required to build an environment that emphasizes mutual respect, mutual trust, and cooperation among employees and departments. Through cross-functional and diverse teamwork at all levels, the organization's strategic goals, vision, and the maintenance of its competitive edge are synergistically achieved (Wood, 1997). Internal cooperation also requires sharing with all members of the organization the mission, values, vision, strategic goals, expected quality standards, and any other necessary information that helps the organization perform at its optimum.

In a high school environment, principals must establish an environment that encourages teamwork. Lasting and significant changes will not occur unless educators and the other staff are directly and actively involved in the planning and development of desired changes (Spanbauer, 1995).

\subsubsection{External Cooperation}

External cooperation is about managing a network of external stakeholder relationships (direct and indirect customers, suppliers, distributors, competitors, the government, etc.) in a way that supports achieving the organization's strategic goals and vision and maintaining its competitive edge. That is, establishing mutually beneficial long-term cooperation with external stakeholders, especially with supply chain members, in order to ensure quality inputs, processes, outputs, and outcomes. It involves educating external stakeholders on the quality standards of the organization, selecting dependable quality-oriented suppliers and distributors, and establishing stakeholder teams that provide suggestions for overall organization success (Khan, 2006).

In the high school environment, principals and the administrative team are responsible for strengthening the bond with external stakeholders through win-win activities in addition to finding different ways of obtaining valuable feedback on ways to improve the performance of the school and the caliber of the graduated students. Thus the administration needs to 
communicate with and educate parents, establish cooperative relationships with potential employers, and insure that faculty and staff are also actively involved in these relationships.

\subsubsection{Linking Internal and External Cooperation}

For optimal performance, internal and external stakeholders need to be connected. Establishing an effective and efficient integration of internal-external stakeholder activities can involve formation of teams that support performance improvement, excellence, and growth leading to the betterment of the organization. These teams should meet regularly and be in regular communication with each other.

In the school environment, principals should build a culture of stakeholder teamwork that includes the employees, parents, business community leaders, and the community as a whole for the betterment of the school (Hemmen et al., 2009).

\subsubsection{Organizational Learning (Education and Training)}

Organizational learning requires the establishment of a supportive learning environment that benefits employees and the organization. Improved performance results from formal and informal learning activities both internal and external to the organization. With the full support of all levels of management, the learning activities aim to build competencies that lead to continuous improvements in productivity. The quality of inputs, processes, outputs, and outcomes required to meet current and future organizational needs are also enhanced by education and training (Feigenbaum, 1986; Senge, 1990).

Within a high school environment, principals must work with all stakeholders to build a supportive learning environment for the staff as well as the students (Pasi, 2003). This environment should inspire teachers to want to learn how they can better meet the academic needs of their students (Daresh, 2001) and motivate students to become life-long learners.

\subsubsection{Process Management}

Although not always visible, work in all organizations is carried out through processes. There are primary, support and managerial processes. The TQM philosophy requires process management with a focus on achieving total quality both in the way the process steps are carried out and in the outputs produced. It is essential that processes have measurable goals, are well designed, and are streamlined. However, even these criteria cannot guarantee success if they are not managed properly (Rummler \& Brache, 1995). Therefore, process management requires planning, organizing, staffing, leading, and controlling the organizational processes. The main objective is to identify any malfunctioning process, correct it, and continually monitor the process. Through the use of carefully chosen performance indicators that measure the performance of critical process steps, incremental improvements in the process performance can be made to meet or raise process standards. Measurement is the basis for process management and requires maintaining up-to-date databases (Khan, 2006). Data obtained from key performance indicators must be timely and easily accessible to users if it is to be useful in managing quality (Douglas \& Fredendall, 2004). The goal of process management is to achieve organizational strategic goals and meet 
or exceed internal and external customer expectations in the most efficient and effective way.

Principals and their administrative team should set initial performance standards that are both clear to everyone and operational. Together with stakeholders, they must design teaching, learning, administrative, and other processes to meet these standards, constantly monitor them with appropriate performance indicators, evaluate the performance, and make adjustments and improvements as necessary in order to achieve the desired school outcomes.

\subsubsection{Continuous Improvement}

An essential part of Deming Philosophy is for leadership to establish a culture of continuous improvement. This is essential because internal and external products are the output of all processes. By paying attention to the characteristics of processes and enhancing their performance, improved quality of their outputs is virtually guaranteed.

The heart of TQM, continuous improvement is a journey of proactive gradual change undertaken by the members of the organization for the purpose development and growth. It is an on-going team effort to improve total organizational performance as a means of achieving strategic goals and vision. Initially there will be many areas of improvement. Parts of the organization having trouble meeting performance or quality improvement goals, or products not meeting or exceeding customer expectations for example are potential areas of focus. Internally, employee morale, loyalty, empowerment, and commitment may need attention. Increasing efficiency by streamlining and eliminating costly waste, increasing both sales and productivity, improving communication and strengthening relationships between stakeholders all may benefit from scrutiny and planning (Anderson et al., 1994). Above all, continuous improvement requires a learning environment that permits and encourages learning from mistakes and sharing this valuable knowledge, instead of a punitive one that punishes mistakes.

Within a high school environment, quality education demands a process of continuous improvement that systematically and collectively evaluates and refines the school's processes, practices, and culture in order to meet or exceed the needs of its stakeholders. Continuous improvement of school processes results in high quality graduates (Evan \& Lindsay, 2002).

\subsubsection{Employee Fulfillment}

Management at all levels must believe that employees are their most important and valuable resource. They must continuously provide a healthy working environment in which employees know how they add value, feel their importance, are treated well, are empowered to be creative and innovative problem solvers, planners, decision makers, and quality performance improvers. Employees at all levels need to be challenged with stimulating tasks and greater responsibilities which add to their competencies and personal growth. Such an environment typically results in loyal employees who are proud to be part of the organization, and are motivated to give their very best even when that means going the extra mile. Simply stated, they feel total satisfaction and enjoy coming to work. 
In a high school environment, the principal and the administrative staff must build an inclusive culture and nurturing environment that allows everyone a voice in decisions. Faculty and staff must have freedom to experiment with performance enhancements that directly affect them without having to seek bureaucratic permission. A nurturing environment results in a pleasant experience for teachers because they are empowered to make necessary changes in teaching methods as they see fit, are highly motivated to achieve excellence, are fulfilled by their jobs, and take pride in their work (Hemmen et al., 2009). Teams should be formed to address problems by applying the correct tools and scientific approaches in a shared decision-making atmosphere (Spanbauer, 1995).

\subsection{Outcome Variables}

\subsubsection{Internal/External Customer Satisfaction}

In TQM, the term "customer" includes both internal and external customers. In the case of a high school, internal customers include school employees at all levels (principal, staff, teachers, and students) while the external customers would include the other stakeholders, including the students. Hence, the student is both an internal and external customer. Internal because of the role he or she plays as a co-worker in learning what is being delivered by the school and external because his or her education is the purpose for schools to exist.

TQM philosophy endeavors to deliver quality products consistently, thereby striving for and achieving customer satisfaction. A requirement of this goal is that input, process, and output must be reliable and consistent. This aspect of TQM has been shown to work well in manufacturing. However, the variability of the student in the process is not something that can be controlled; even a quality education cannot guarantee an exceptional graduate, or a satisfied external customer. In fact, we observed that principals and their administrative staff in Kuwaiti public high schools consider assuring the delivery of quality education a strategic outcome by itself. That is, if they are successful in achieving this goal they have done their job, and are secure in the belief that it may be impossible to satisfy every customer. That is, we believe that many of the Kuwaiti educators we encountered consider the delivery of quality education to be the central part of their mission; that by delivering an internal outcome, the external outcome of stakeholder satisfaction will result on its own.

As a result of this observation, we propose adding the concept of School Assured Satisfaction as an eighth construct in The Deming Management Model (Anderson et al., 1994). This will be further illustrated in Section 4.

\subsubsection{School Assured Satisfaction (Internal Customer Satisfaction)}

School Assured Satisfaction refers to the satisfaction that all school employees get from doing their best to assure the delivery of quality education (the school's product). This satisfaction is increased when school employees see a successful student who responded positively to the educational process. Student success, though hoped for, cannot be guaranteed. As mentioned previously, the variable nature of each student has an impact on the school's product. All activities directed towards assuring a quality product (quality education) are referred to in this paper as assured satisfaction activities. They include 
proactive quality assurance activities carried out by all employees at all levels, as well as the various school processes that assure delivery of the product. Successful delivery will result in satisfaction of internal and external customers and stakeholders (i.e., students, parents, higher education institutions, and employers). To ensure the delivery of content quality, school leadership must establish a strong foundation of appropriate quality systems, processes, teaching style, and environment (Tribus, 1992).

\subsubsection{Customer Satisfaction (External Customer Satisfaction)}

Organizations are established to add value to society through the products they offer to their customers. Value is added when the products satisfy the needs and wants of the customer. From the perspective of the customer, products are of quality when these needs and wants are fulfilled consistently. When this occurs, the organization will have achieved customer satisfaction. If the organization is able to consistently exceed customer expectations, it is likely to result in customer loyalty. Loyal customers make the organization part of their lives share their satisfaction with others, in effect contributing to marketing efforts (Blanchard \& Bowles, 1995).

For service organizations, customer satisfaction includes both the quality of the product and the quality of the service delivery. The entire transaction, and not just the outcome, are of great importance to the customer. For example, the way in which a teacher explains the material and treats the student will influence the behavior, attitude, and the opinion held by the student toward not just the teacher but the entire organization, and even about education generally. A positive attitude toward the teacher, school, and regarding education impacts motivation and learning. These moments of interaction between service provider (contact personnel) and customer are known as "moments of truth" (Fitzsimmons \& Fitzsimmons, 2008). Each time one of these interactions occur, the customer will evaluate the quality level of the interaction and thus form or modify an opinion of the quality level of the service organization. Hence, it is crucial to design and operate each moment of truth with assured quality processes to positively influence the customer's perception of the service quality and thus assure customer satisfaction. This requires continual knowledge of customer requirements and expectations. For high schools, this could involve obtaining valuable feedback about the school's performance from teachers, support staff, alumni, current students, parents, higher education institutions, and the market through periodic surveys, quality improvement meetings, focus groups, and other close-contact means for obtaining stakeholder feedback. By designing and operating a quality assurance feedback system the service organization can be confident that it is meeting current customer expectations and customer satisfaction should be the ultimate result. Service quality leads to customer satisfaction (Cronin \& Taylor, 1992).

Once again it is important to emphasize that students are not parts manufactured in a factory. A high school may operate the best education system, but if the student does not interact with it and do his or her part (i.e., studying, doing home works and projects, etc.), then the results may be less than satisfactory - at least for the under motivated student. Even if the school processes are designed and operated with a focus on assured quality education, one hundred 
percent stakeholder satisfaction cannot be assured. Given the dual nature of the student as both worker and customer, it is important that processes and mechanisms be put in place to both motivate students and to provide early warning for students not performing. Failure to detect and remedy problems such as lack of student motivation can have far-reaching negative impact on the school and its reputation with stakeholders.

In the next section a conceptual model along the lines of Deming and Anderson et al. (1994) with a suggested modification, is proposed and explained. This will be followed by model building, path analysis, verification of research hypotheses, and finally the research findings, recommendations, and conclusion.

\section{The Proposed Model}

It is well known that leadership is a key element in effective organizations. As illustrated in the figure, the proposed model of the current study is similar to that presented by Anderson et.al (1994).

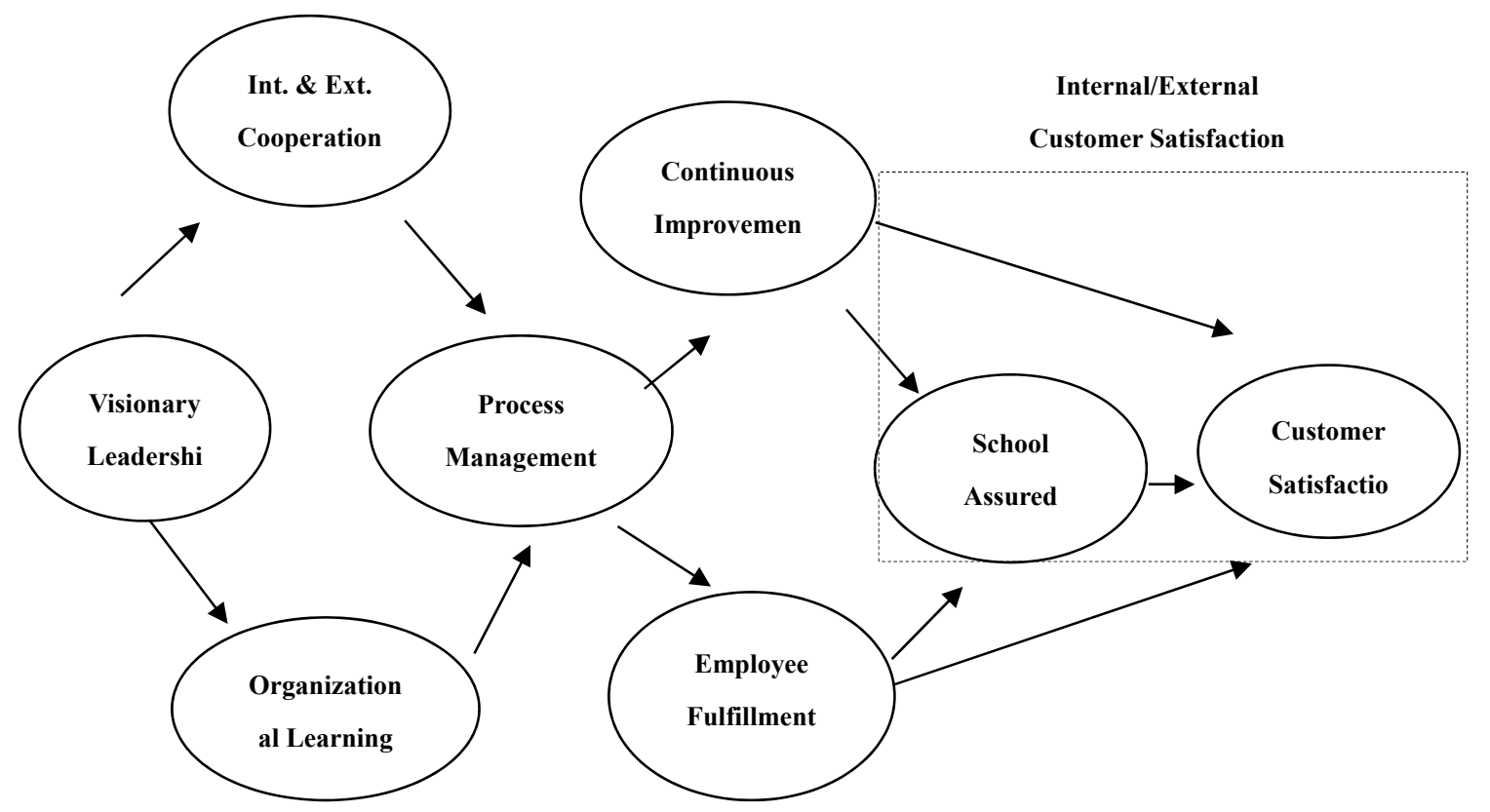

It starts with visionary leadership which stimulates the process of assuring quality and satisfaction via several moderating effects which in turn together contribute to the impact on two final outcomes. Although the analyses will provide all encountered effects (direct, indirect, and total effects), this research will focus primarily on total effects of the exogenous variable and moderators on the outcomes.

\subsection{The Research Hypotheses}

The main objective in this section is to assert the following three main hypotheses $\left(H_{a}-H_{c}\right)$. For the first two hypotheses $\left(H_{a}\right.$ and $\left.H_{b}\right)$, we derive six sub-hypotheses to examine the total 
effects of all contextual variables on each of the School Assured and the Customer Satisfaction constructs. The third main hypothesis $\left(H_{c}\right)$ investigates the direct effect of the School Assured Satisfaction construct on the Customer Satisfaction construct.

For each of the following hypotheses, there is a positive total effect of...

$H_{a}: \quad \ldots$ each TQM determinant on school assured satisfaction

$H_{a 1}$ : ... visionary leadership on school assured satisfaction

$H_{a 2}: \ldots$ internal and external cooperation on school assured satisfaction

$H_{a 3}$ : ... organizational learning on school assured satisfaction

$H_{a 4}:$... process management on school assured satisfaction

$H_{a 5}:$... continuous improvement on school assured satisfaction

$H_{a 6}$ : ... employee fulfillment on school assured satisfaction

For each of the following hypotheses, there is a positive total effect of...

$H_{b}:$... each TQM determinant on customer satisfaction

$H_{b 1}: \ldots$ visionary leadership on customer satisfaction

$H_{b 2}: \ldots$ internal and external cooperation on customer satisfaction

$H_{b 3}: \ldots$ organizational learning on customer satisfaction

$H_{b 4}:$... process management on customer satisfaction

$H_{b 5}:$... continuous improvement on customer satisfaction

$H_{b 6}$ : ... employee fulfillment on customer satisfaction

$H_{c}$ : There is a positive direct effect of school assured satisfaction on customer satisfaction

\subsection{Survey Design and Data Collection}

To operationalize the above objectives, a survey study was designed and a structured questionnaire devised along the lines of the contextual and outcome variables discussed above. Instruments were designed within the framework established by Anderson et al. (1994) with major modifications to the service sector, namely high school education. Instruments were reviewed and modified to fit and match the culture of the Middle East. After developing the questionnaire, a random pilot sample of 200 subjects was collected from different public schools in Kuwait to test the instruments and to check both reliability and validity of the questionnaire. Some instruments were dropped due to either irrelevancy or to reduce the number of questions to maximize the explained variance. Although the original TQM concepts were measured by 38 instruments, they were later reduced to 24 instruments due to lack of reliability or validity.

Having analyzed and revised the questionnaire, a random sample of 2000 subjects (principals, 
teachers, staff, parents) were collected from public high schools in Kuwait using a stratified random sample method. Complete forms of the questionnaire were collected over a two month period and analyzed. The overall reliability was high (Cronbach's $\alpha=94.2 \%$ ) which illustrates an acceptable consistency among instruments. Structural Equation Modeling, using both exploratory and confirmatory factor analysis statistical techniques, was employed to confirm and validate the measuring instruments of each construct. The fitted model is useful in understanding the cause and effect relationship among the contextual and outcome variables.

\subsection{Sample Characteristics}

Gender distribution in the sample was $78.5 \%$ females and $21.5 \%$ males. Stakeholder classification characteristics of the sample: $1 \%$ were principals, $1.5 \%$ were assistants, $91 \%$ were teachers and staff, and $6.5 \%$ were parents. The distribution of their qualifications was as follows: $9.8 \%$ high school graduates, $83.3 \%$ were university graduates, and $6.9 \%$ had postgraduate degrees. The distribution of working experience: less than 5 years: $38.46 \%$; between 5 - 10 years: 26.14\%; between 11 - 15 years: $17.7 \%$; and more than 15 years: $17.7 \%$.

\section{Data Analysis}

\subsection{Factor Analysis for Instruments Screening}

In this section we utilize factor analysis techniques to reduce the number of questions to a lesser number of surrogated variables called latent variables (factors) using orthogonal rotation. These factors will serve as the basic building blocks of the proposed structural equation model. Table (1) below presents the reduced factors, their explained variances, associated factor loadings, and reliability coefficients. As indicated in the table, the reliabilities of all factors are more than $79 \%$ which assures an acceptable level of internal consistency of the factors (recommended $70 \%$ or more). The extracted variances (explained) are all above $70 \%$ which again is above the agreeable acceptable level (Hair et al., 2010). Table (1) presents the most reliable and valid items.

Table 1. Explained Variance, Factor Loading and Reliability Coefficient

\begin{tabular}{lllll}
\hline & Factors & $\begin{array}{c}\text { Explained } \\
\text { Variance }\end{array}$ & $\begin{array}{l}\text { Factor } \\
\text { Loading }\end{array}$ & Reliability \\
\hline & Visionary Leadership & $\mathbf{7 0 . 6 2 \%}$ & & $\mathbf{7 9 . 1 \%}$ \\
$\mathbf{1}$ & Identification of School Difficulties & & $\mathbf{0 . 8 4 2}$ & \\
$\mathbf{2}$ & stakeholders Involvement in Strategic Planning & & $\mathbf{0 . 8 2 9}$ & \\
$\mathbf{3}$ & Determination of Targeted Service Quality & $\mathbf{0 . 8 5 0}$ & \\
& Internal / External cooperation & $\mathbf{7 3 . 0 3 \%}$ & & $\mathbf{8 1 . 1 \%}$ \\
$\mathbf{1}$ & Team Problem Solving Delegation & & $\mathbf{0 . 8 2 8}$ & \\
$\mathbf{2}$ & Encouraging Internal Communication & & $\mathbf{0 . 8 7 1}$ & \\
$\mathbf{3}$ & Strengthening Stakeholder Relationships & & $\mathbf{0 . 8 6 4}$ & \\
& Organizational Learning & $\mathbf{7 3 . 1 1 \%}$ & & $\mathbf{8 1 . 4 \%}$ \\
\hline
\end{tabular}


1 Identification of stakeholders Training Needs

2 Emphasizing the Importance of Acquiring Skills

0.878

3 Paying Attention to employee performance

0.847

Enhancement

\section{Process Management}

1 Comprehensive evaluation of the teaching process

2 Administration conducts studies to measure service quality

3 The administration is concerned with the relevancy of its services.

\section{Continuous Improvement}

1 Providing an appropriate working conditions

2 Providing an appropriate classroom environment

3 Providing fully equipped facilities to support the teaching process

\section{Employee Fulfillment}

1 Administration listens to teacher's opinion

2 Administration-teachers jointly resolves teacher's problems

3 Administration delegates decision making to teachers

\section{Internal/External Customer Satisfaction}

School Assured Satisfaction

1 Trusting employees to develop self-monitoring and correction of their performance

2 Developing the principle of work perfection within employees

3 Encouraging teachers to suggest creative ideas for improvement

\section{Customer Satisfaction}

1 Administration ensures satisfactory responses to service inquiries

2 Administration facilitates communication with stakeholders

3 Administration quickly fulfills stakeholder needs $\mathbf{7 2 . 5 4 \%}$

81. \%

0.769

0.888

0.893

$76.04 \%$

$84.1 \%$

0.841

0.895

0.880

$\mathbf{7 7 . 4 3 \%}$

$85.3 \%$

0.878

0.900

0.861

$71.47 \%$

$79.9 \%$

0.864

0.870

0.800

82.68\%

$89.5 \%$

0.903

0.920

0.905

Having reduced the research items to a lesser number of surrogated variables (constructs) via factor analysis, we expressed each construct as a weighted average of the most reliable and valid items weighted by their corresponding factor loadings. Table (2) presents statistical summary measures of all TQM surrogated constructs. As shown in Table (2) all averages are larger than 3 (on a 5 point Likert scale) and also significant $(p<0.05)$ as shown in the last column, which indicates a positive perception towards all TQM constructs from the respondents' standpoint. The results indicate initial fulfillment of both school and customer 
satisfaction outcomes in addition to an overall agreement that TQM elements are being practiced to a good extent in the schools. However, a rigorous account will be given to the interrelationships between different constructs subsequently to assert the proposed hypotheses regarding the outcomes. Verification of the proposed research hypotheses and path analysis discussion are presented once the model is fitted to the collected survey data as shown in the next section.

Table 2. Descriptive Statistics of Research Constructs

\begin{tabular}{lllll}
\hline TQM Constructs & $\mathrm{N}$ & Mean & $\begin{array}{l}\text { Std. } \\
\text { Deviation }\end{array}$ & $p$-value \\
\hline Visionary Leadership & 2000 & 4.0088 & 0.96544 & $<0.001^{*}$ \\
Internal / External cooperation & 2000 & 4.0754 & 0.91191 & $<0.001^{*}$ \\
Learning & 2000 & 4.0312 & 0.92493 & $<0.001^{*}$ \\
Process Management & 1999 & 3.8161 & 1.08736 & $<0.001^{*}$ \\
Continuous Improvement & 2000 & 4.1154 & 0.89134 & $<0.001^{*}$ \\
Employee Fulfillment & 2000 & 3.9152 & 0.97327 & $<0.001^{*}$ \\
School Assured Satisfaction & 2000 & 4.2432 & 0.84044 & $<0.001^{*}$ \\
Customers Satisfaction & 2000 & 3.9982 & 1.06627 & $<0.001^{*}$ \\
\hline
\end{tabular}

*the result is significant at $\alpha<0.05$

\subsection{The Fitted Model}

After preparing the correlation matrix between the most reliable and valid questions (indicators), we utilized Structural Equation Modeling (SEM) to fit the proposed conceptual model against other alternatives. Several measures of goodness of fit were considered to select the best fitted model. Including, Normed Fit Index (NFI) $=0.99$, Non-Normed Fit Index $(\mathrm{NNFI})=0.99$, Incremental Fit Index $(\mathrm{IFI})=0.99$, Relative Fit Index $(\mathrm{RFI})=0.98$, Critical N $(\mathrm{CN})=228.90, \quad$ Root Mean Square Residual $(\mathrm{RMR})=0.044$, Standardized RMR $=0.044$, Goodness of Fit Index $(\mathrm{GFI})=0.90$, Adjusted Goodness of Fit Index (AGFI) $=$ 0.87, Parsimony Normed Fit Index $(\mathrm{PNFI})=0.80$, Comparative Fit Index $(\mathrm{CFI})=0.99$. All measures of goodness of fit indices indicate that the proposed model is adequate in fitting the data. In particular, RMR $=0.044$ (recommended 0.05 or less; Hair et al., 2010), GFI $=0.90$, recommended 0.85 or more and AGFI $=0.87$, recommended 0.80 or more, which are satisfactory measures of goodness of fit (see Hair et al., 2010; and Sharma, 1996 for details). Table (3) below, provides statistical summary measures of each construct including composite reliability and variance extracted for all constructs. Moreover, the coefficient of determination $R^{2}$ of the endogenous variables is also presented.

Having arrived at a fitted model, both composite reliability and extracted variance of each construct can be assessed. We would like to stress that Cronbach's $\alpha$, the reliability coefficient, given in Table (1), last column, does not ensure the unidimensionality of the construct but contrarily assumes it exists (see Hair et al., 2010 for details). Therefore composite reliability which is a measure of internal consistency is a more reliable alternative measure and is calculated, for each construct, by the following formula: 


$$
\text { Composite Reliability }=\frac{\left(\sum \text { Standardized loadings }\right)^{2}}{\left(\sum \text { Standardized loadings }\right)^{2}+\sum \mid \text { error } \mid}
$$

Where: standardized loadings and associated errors are calculated by the structure equation technique among LISREL output.

Table 3. Measures of Model Adequacy

\begin{tabular}{llll}
\hline Construct & $\begin{array}{l}\text { Composite } \\
\text { Reliability }\end{array}$ & $\begin{array}{l}\text { Variance } \\
\text { Extracted } \\
\text { (AVE) }\end{array}$ & $\boldsymbol{R}^{\mathbf{2}}$ \\
\hline Visionary Leadership & $86 . \%$ & $66 . \%$ & ----- \\
Internal/External cooperation & $87.3 \%$ & $69.6 \%$ & $65 \%$ \\
Organization Learning & $87.9 \%$ & $70.8 \%$ & $72 \%$ \\
Process Management & $83.3 \%$ & $63.3 \%$ & $67 \%$ \\
Continuous Improvement & $89.3 \%$ & $73.5 \%$ & $78 \%$ \\
Employee Fulfillment & $89.4 \%$ & $73.9 \%$ & $73 \%$ \\
School Assured Satisfaction & $86.5 \%$ & $58.2 \%$ & $89 \%$ \\
Customers Satisfaction & $93.8 \%$ & $82.6 \%$ & $83 \%$ \\
\hline
\end{tabular}

The second column in Table (3) presents values of the construct composite reliability. As common practice, composite reliability $70 \%$ or more is acceptable (Hair et al., 2010). As shown, all composite reliabilities are above $83 \%$ which is higher than the threshold given in Hair et al., (2010) and Sharma (1996). Another measure of internal reliability is the variance extracted; the measure evaluates the overall amount of explained variations accounted for by the instruments. Variance extracted of $50 \%$ or more is considered adequate (Hair et al., 2010; Sharma, 1996). The variance extracted is computed by the following formula:

$$
\text { Variance extracted }=\frac{\sum(\text { Standardized loadings })^{2}}{\sum(\text { Standardized loadings })^{2}+\sum \mid \text { error } \mid}
$$

Column 3 of Table (3) shows that the values of the extracted variance are greater than $58 \%$ for all constructs. Regarding the coefficient of determination, $R^{2}$, values presented in the last column of Table (3), all values indicate satisfactory explanation to all endogenous constructs.

Overall, the stated measures of model goodness of fit in this section confirm the adequacy of the proposed model. With this confirmation it would be of interest to study the linear correlation between constructs to assess the strength and direction of the linear relationship between each pair. These values may be of importance in better understanding and trying to explain the nature of the total impact that constructs have on the outcome variables. The results of these analyses are presented in the following section.

\subsection{The Correlation Structure}

Correlation measures the direction and the strength of the linear relationship between two variables. As shown in Table (4) below, there is strong positive and significant correlation between Visionary Leadership and Internal and External Cooperation $(r=0.81, p<0.001)$, 


\section{Ml Macrothink}

International Journal of Education

ISSN 1948-5476

2015, Vol. 7, No. 2

Organizational Learning ( $r=0.77, p<0.001)$, Process Management $(r=0.74, p<0.001)$, Continuous Improvement $(r=0.75, p<0.001)$, Employee Fulfillment $(r=0.72, p<0.001)$, Assured Satisfaction $(r=0.75, p<0.001)$, and Customers Satisfaction $(r=0.71, p<0.001)$. Likewise, Internal and External Cooperation has a strong positive and significant correlation with Organization Learning $(r=0.83, p<0.001)$, Process Management $(r=0.76, p<0.001)$, Continuous Improvement $(r=0.80, p<0.001)$, Employee Fulfillment $(r=0.79, p<0.001)$, Assured Satisfaction $(r=0.86, p<0.001)$, and Customer Satisfaction $(r=0.77, p<0.001)$. The remaining entries in Table (4) exhibit similar patterns and can be explained in exactly the same way, we omit details for brevity.

Table 4. Correlation between the Measurements Variables

\begin{tabular}{|c|c|c|c|c|c|}
\hline 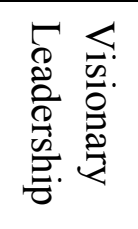 & 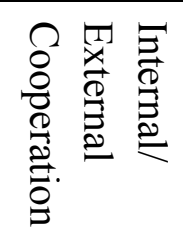 & 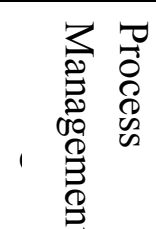 & 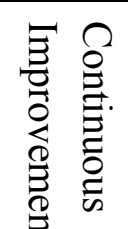 & 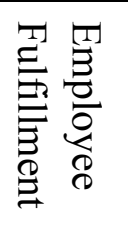 & 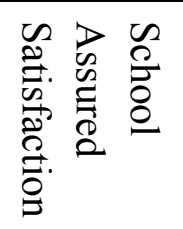 \\
\hline
\end{tabular}

\begin{tabular}{|c|c|c|c|c|c|c|c|c|}
\hline $\begin{array}{l}\text { Visionary } \\
\text { Leadership }\end{array}$ & 1 & & & & & & & \\
\hline$p$-value & $(0.000)$ & & & & & & & \\
\hline $\begin{array}{l}\text { Internal/ External } \\
\text { Cooperation }\end{array}$ & 0.81 & 1 & & & & & & \\
\hline$p$-value & $(0.000)$ & $(0.000)$ & & & & & & \\
\hline $\begin{array}{l}\text { Organizational } \\
\text { Learning }\end{array}$ & 0.77 & 0.83 & 1 & & & & & \\
\hline$p$-value & $(0.000)$ & $(0.000)$ & $(0.000)$ & & & & & \\
\hline $\begin{array}{l}\text { Process } \\
\text { Management }\end{array}$ & 0.74 & 0.76 & 0.78 & 1 & & & & \\
\hline$p$-value & $(0.000)$ & $(0.000)$ & $(0.000)$ & $(0.000)$ & & & & \\
\hline $\begin{array}{l}\text { Continuous } \\
\text { Improvement }\end{array}$ & 0.75 & 0.80 & 0.80 & 0.77 & 1 & & & \\
\hline$p$-value & $(0.000)$ & $(0.000)$ & $(0.000)$ & $(0.000)$ & $(0.000)$ & & & \\
\hline $\begin{array}{l}\text { Employee } \\
\text { Fulfillment }\end{array}$ & 0.72 & 0.79 & 0.74 & 0.81 & 0.84 & 1 & & \\
\hline$p$-value & $(0.000)$ & $(0.000)$ & $(0.000)$ & $(0.000)$ & $(0.000)$ & $(0.000)$ & & \\
\hline $\begin{array}{l}\text { School Assured } \\
\text { Satisfaction }\end{array}$ & 0.75 & 0.86 & 0.85 & 0.78 & 0.89 & 0.87 & 1 & \\
\hline$p$-value & $(0.000)$ & $(0.000)$ & $(0.000)$ & $(0.000)$ & $(0.000)$ & $(0.000)$ & $(0.000)$ & \\
\hline $\begin{array}{l}\text { Customer } \\
\text { Satisfaction }\end{array}$ & 0.71 & 0.77 & 0.72 & 0.89 & 0.78 & 0.77 & 0.80 & 1 \\
\hline$p$-value & $(0.000)$ & $(0.000)$ & $(0.000)$ & $(0.000)$ & $(0.000)$ & $(0.000)$ & 0.000 & $(0.000)$ \\
\hline
\end{tabular}

5.4 Path Analysis and Confirmation of Research Hypotheses

Having reached the final fitted model which satisfies all predetermined statistical 
requirements, it would be of interest at this point to examine the research hypotheses proposed in this study. The following table, Table (5), illustrates the significance of all encountered hypotheses which signifies the existence of total effects. The table presents all possible paths to each outcome along with, path coefficient (total effect), standard error, t-value, $\mathrm{p}$-value, and the corresponding hypothesis.

Table 5. Path Analysis

\begin{tabular}{|c|c|c|c|c|c|}
\hline Path & 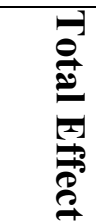 & 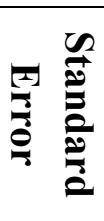 & $\frac{\bar{\pi}}{\frac{\pi}{\partial}}$ & 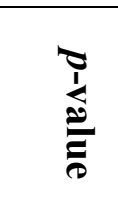 & 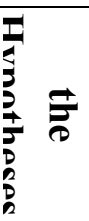 \\
\hline Visionary Leadership $\rightarrow$ Assured Satisfaction & 0.78 & 0.02 & 31.25 & 0.000 & $H_{a 1}$ \\
\hline Visionary Leadership $\rightarrow$ Customers Satisfaction & 0.71 & 0.02 & 31.36 & 0.000 & $H_{b 1}$ \\
\hline Int.\& Ext. Cop. $\rightarrow$ Assured Satisfaction & 0.76 & 0.04 & 19.22 & 0.000 & $H_{a 2}$ \\
\hline Int.\& Ex. Cop $\rightarrow$ Customers Satisfaction & 0.57 & 0.04 & 15.04 & 0.000 & $H_{b 2}$ \\
\hline Organizational Learning $\rightarrow$ Assured Satisfaction & 0.42 & 0.04 & 11.18 & 0.000 & $H_{a 3}$ \\
\hline Organizational Learning $\rightarrow$ Customers Satisfaction & 0.22 & 0.04 & 5.63 & 0.000 & $H_{b 3}$ \\
\hline Process Management $\rightarrow$ Assured Satisfaction & 0.19 & 0.03 & 5.67 & 0.000 & $H_{a 4}$ \\
\hline Process Management $\rightarrow$ Customers Satisfaction & 0.82 & 0.04 & 22.93 & 0.000 & $H_{b 4}$ \\
\hline Continues Improvement $\rightarrow$ Assured Satisfaction & 0.34 & 0.04 & 9.54 & 0.000 & $H_{a 5}$ \\
\hline Continuous Improvement $\rightarrow$ Customers Satisfaction & 0.20 & 0.04 & 5.67 & 0.000 & $H_{b 5}$ \\
\hline Employee Fulfillment $\rightarrow$ Assured Satisfaction & 0.48 & 0.03 & 14.74 & 0.000 & $H_{a 6}$ \\
\hline Employee Fulfillment $\rightarrow$ Customers Satisfaction & 0.07 & 0.03 & 2.27 & 0.000 & $H_{b 6}$ \\
\hline Assured Satisfaction $\rightarrow$ Customers Satisfaction & 0.33 & 0.07 & 5.12 & 0.000 & $H_{c}$ \\
\hline
\end{tabular}

As shown in Table (5), there is a strong positive significant total effect $(78 \%, p<0.001)$ of Visionary Leadership on School Assured Satisfaction which supports $H_{a 1}$. It is also evident that Visionary Leadership has a strong positive and significant $(71 \%, p<0.001)$ total effect on Customer Satisfaction which justifies $H_{b 1}$. Int. \& Ext. Cooperation has a strong positive and significant total effect $(76 \%, p<0.001)$ on School Assured Satisfaction which confirms $H_{a 2}$, while it has a strong total effect $(57 \%, p<0.001)$ on Customer Satisfaction which asserts $H_{b 2}$. Organizational Learning, on the other hand, has a moderate positive but significant total effect $(42 \%, p<0.001)$ on School Assured Satisfaction which validates $H_{a 3}$, while it has a weak positive but total significant effect $(22 \%, p<0.001)$ on Customer Satisfaction which affirms $H_{b 3}$. Process Management has a weak positive but significant total effect $(19 \%, p<0.001)$ on School Assured Satisfaction which defends $H_{a 4}$, on the contrary, it has a strong positive and significant total effect $(82 \%, p<0.001)$ on Customer Satisfaction which validates $H_{b 4}$. Next, Continuous Improvement has a moderate positive but significant total effect $(34 \%, p<0.001)$ on School Assured Satisfaction which alleges $H_{a 5}$. It also follows that it has a weak positive but significant total effect $(20 \%, p<0.001)$ on Customer Satisfaction which establishes $H_{b 5}$. Employee Fulfillment has a moderate positive but significant total effect $(48 \%, p<0.001)$ on School Assured Satisfaction which 
demonstrates $H_{a 6}$, and a weak positive but significant total effect $(7 \%, p<0.001)$ on Customer Satisfaction which substantiates $H_{b 6}$. Finally, School Assured Satisfaction has a moderate direct positive but significant effect $(33 \%, p<0.001)$ on Customer Satisfaction which authenticates the hypothesis $H_{c}$.

\section{Findings \& Conclusions}

\subsection{Purpose of Study}

It is truly a challenge for a public high school to be able to deliver an education system whose outcomes include lifelong learners with an ability to grow in knowledge, knowhow, wisdom, and character. To both effectively and efficiently meet this challenge, TQM concepts offer promise and are worthy of attention. The purpose of this study was to investigate the degree to which our proposed TQM model, a slightly modified version of the Anderson et al. (1994) TQM model, is applicable to public high school education in Kuwait. In particular we were interested in studying the total effect that each construct had on the internal outcome of school satisfaction resulting from assuring the delivery of quality education and on the external outcome of customer satisfaction. We were also interested in discovering the degree to which TQM concepts were actually being applied in the field. This would help us better predict the chances of the MOE succeeding in their TQM project in public schools as well as to provide data and insight to assist in that project.

\subsection{Major Findings}

It was gratifying to find that the average response computed for each construct, see Table (2), indicate that there is an overall positive feeling that TQM concepts are already being applied in Kuwaiti high schools. This result offers support for the prediction that the MOE can succeed in operating all public schools using TQM.

Secondly, the rearrangement of the results of path analysis in Table (5) leads to Table (6) from which a few important observations can be made. As shown, there are two constructs that clearly have a high total effect on Customer Satisfaction: Process Management $(82 \%)$ and Visionary Leadership (71\%). Internal/External Cooperation, on the other hand, has only a fairly strong total effect on Customer Satisfaction (57\%). Visionary Leadership (78\%) and Internal/External Cooperation (76\%) have a high total effect on School Assured Satisfaction. Moreover, both Visionary Leadership and Internal/External Cooperation have a strong total effect that is higher on School Assured Satisfaction than on Customer Satisfaction. Process Management has the highest total effect of all constructs on Customer Satisfaction (82\%) but the lowest total effect (19\%) on School Assured Satisfaction.

Note that Visionary Leadership is the only construct with a high total effect on both School Assured Satisfaction (78\%), and Customer Satisfaction (71\%). This supports what was said earlier that leadership is of prime importance to the success of any organization. Internal/External Cooperation, on the other hand, has a higher total effect on School Assured Satisfaction (76\%) than on Customer Satisfaction (57\%). The moderate direct effect of 
School Assured Satisfaction on Customer Satisfaction (33\%) justifies adding this construct to the model although it was expected to have greater influence. This supports our argument that even if a school is doing its best to deliver quality education, that alone does not necessarily lead to customer satisfaction. To get a more realistic view of school success, therefore, we recommend adding the School Assured Satisfaction construct to the model, at least in studying high school education in Kuwait. Further research is needed to assess the relevance of the School Assured Satisfaction construct elsewhere. Organizational Learning has a stronger total effect on School Assured Satisfaction (42\%) than on Customer Satisfaction $(22 \%)$. Continuous Improvement surprisingly has a moderate total effect on School Assured Satisfaction (34\%) and a weak total effect on Customer Satisfaction (20\%) even though continuous improvement should lead to stronger total effects since it is an indicator of on-going improvement of performance. Employee Fulfillment has an unexpected weak total effect on Customer Satisfaction (7\%, the weakest total effect of any measured) and a moderate total effect on School Assured Satisfaction (48\%), less than we expected.

Table 6. Total Effects on School Assured Satisfaction and Customer Satisfaction

Table (6) - A

\begin{tabular}{clc}
\hline $\begin{array}{c}\text { Degree of } \\
\text { Impact }\end{array}$ & \multicolumn{1}{c}{ Source of Effect } & $\begin{array}{c}\text { Magnitude of Impact on } \\
\text { School Assured Satisfaction }\end{array}$ \\
\hline Strong & Visionary Leadership & $78 \%$ \\
& Int.\& Ext. Cooperation & $76 \%$ \\
Moderate & Employee Fulfillment & $48 \%$ \\
& Organizational Learning & $47 \%$ \\
& Continuous Improvement & $34 \%$ \\
Weak & Process Management & $19 \%$ \\
\hline
\end{tabular}

Table (6) - B

\begin{tabular}{llc}
\hline $\begin{array}{c}\text { Degree of } \\
\text { Impact }\end{array}$ & \multicolumn{1}{c}{ Source of Effect } & $\begin{array}{c}\text { Magnitude of Impact on } \\
\text { Customers Satisfaction }\end{array}$ \\
\hline Strong & Process Management & $82 \%$ \\
& Visionary Leadership & $71 \%$ \\
& Int. \&Ext. Cooperation & $57 \%$ \\
Moderate & School Assured Satisfaction & $33 \%$ \\
Weak & Organizational Learning & $22 \%$ \\
& Continuous Improvement & $20 \%$ \\
& Employee Fulfillment & $7 \%$ \\
\hline
\end{tabular}

The above findings indicate three main points. First, it seems that principals are leading their schools with a greater emphasis on assuring the delivery of quality education rather than on achieving customer satisfaction per se. This is evident in that the total impact that Visionary Leadership, Internal/External Cooperation, Employee Fulfillment, Organizational Learning, 
and Continuous Improvement each have on School Assured Satisfaction is higher than that on Customer Satisfaction for all of these constructs. This does not mean that principals and their schools do not care about achieving customer satisfaction, but may reflect a realization that pleasing all students, parents, and society is an impossible goal for high school education in Kuwait. A more achievable goal may be to provide quality education, and then let the product of that education (i.e., students) win over the stakeholder customers. More troubling is the possibility that the School Assured Satisfaction mission by itself is seen as a final outcome, when in fact it should be considered a preliminary step toward the final product in the system: Customer Satisfaction. If this is the case, then educators and administrators in the high schools need to be constantly reminded of three things: 1) in education the student is both a worker and the customer and that the product is the effective education of the student; 2) the crucial role of the student in determining their own success and that of the school demands that students be treated as active participants and not passive recipients of knowledge; 3) quality education should include instruction in learning itself, in application, analysis, critical thinking skills, and creative problem solving. By doing this, the ultimate objective of customer satisfaction is more likely to be achieved. Note that it is the duty of the educational system to provide the appropriate environment for the students to achieve this, but success requires the active cooperation and participation of the student.

Secondly, the data suggests that the efforts the principals are putting into strengthening internal/external cooperation, achieving employee fulfillment, and developing organizational learning are having a positive impact on assuring quality education. Therefore, the efforts in these areas should continue with a focus on improving performance in employee fulfillment and organizational learning. Unfortunately, the energy exerted in continuous improvement does not seem to have the impact one would expect it should have on assuring the delivery of quality education. This may be due to the centralized management philosophy that the MOE still follows instead of allowing local schools to tailor their processes to their students. Interviews with school employees revealed a perception that most suggestions for improvement initiated in high schools do not see the light because they don't get approved by the MOE. This may explain why the total effect that continuous improvement has on the two outcomes is not very high. Nevertheless, the total impact that principals have on the two outcomes is high, indicating that their leadership is an important element in the success of their schools.

Finally, process management, which is really the heart of assuring quality education, seems to have very little positive impact on this outcome, and is focused almost totally on assuring customer satisfaction. One would expect the reverse to be true. To try and explain this phenomena, which requires further examination by decision makers in the MOE, it is important to realize that public schools in Kuwait operate according to the MOE's plans, procedures, rules, policies, and allocation of resources. It is in fact these bureaucratic realities that underlie process management in Kuwaiti schools. As an indicator of reality, if path analysis indicates that principals are running their schools with an emphasis on achieving customer satisfaction rather than on achieving quality education, it may be a result of centralized control from the MOE. 
Interviews conducted with school employees indicated that pleasing the community, specifically parents, is an unavoidable practice. "The MOE wants to look good, and seeks to do that mainly by pleasing parents when they bend the rules related to student performance and discipline issues," as one employee put it. This is easily understood, since the Kuwaiti society is a small one made up of interrelated families. Pressure from family members and relatives, favoritism, and special treatment can at times override the procedures, rules and policies previously set by the school or the MOE. Without any doubt, good intentions and positive efforts for delivering quality education were observed, but more assertiveness is needed by the MOE in confronting traditional social pressures so that the total impact of process management can be realized in assuring the delivery of quality education in the high schools. As mentioned in the interviews, "if matters were left up to the schools, things would be different."

\subsection{Recommendations}

The TQM system of Kuwait public high school education is functioning but not as well as it could. The weakest link in assuring the delivery of quality education (based on total impact) is the TQM element Process Management followed by Continuous Improvement. Successful implementation of TQM requires all elements to perform optimally. Therefore, it is recommended that the TQM system that MOE wishes to implement be simple: easy to understand, easy to learn, easy to use, and easy to improve. It should focus on reviving process management and continuous improvement efforts in the schools in addition to improving what is currently being done in the areas of organizational learning and employee fulfillment. It should aim to increase the chances of assuring quality education and decreasing the gap between it and customer satisfaction. In order to achieve this, it is recommended that the MOE along with high school leadership establish a "measure and fix as we go" active managerial system for periodically checking the quality of outputs of the eight TQM constructs throughout the school year instead of only checking outcome performance at the end of each semester. This "on line quality assurance system" would provide a timely snapshot of each school's quality performance indicating what is working well and what needs correction. This would proactively reduce the gap between a school's implicit goal of assuring quality education and the explicit goal of customer satisfaction. The idea is for schools to periodically take leading (anticipatory) measurements associated with Visionary Leadership, Internal/External Cooperation, Organizational Learning, Process Management, Employee Fulfillment, and Continuous Improvement throughout the school year in order to increase the chances of achieving the lagging (confirmatory) measurements associated with both assuring quality education and customer satisfaction. The data on the lead measures will indicate to everyone in the school and the MOE if everything is running properly. That is, how much of a gap exists between what should be done and what is actually being done in each TQM element. It will point out bottlenecks, if any, in the educational process (the school's product) because it focuses on measuring the quality of the output or outcome of each construct. To illustrate, if after the first 45 days of a standard 180 day school year (half way through the semester), it was noticed that there was a negative response in one of the constructs (e.g., internal/external stakeholder cooperation), then correction measures can be 
put in place immediately instead of being taken by surprise at the end of the semester or school year that, e.g., Assured Satisfaction or/and Customer Satisfaction responses were not very high. It is also recommended that the MOE not forget their role as a partner. Working alone away from the field will not lead to promising outcomes. The system needs to be run cooperatively by the people in the schools and in MOE offices. Enhanced cooperation would also ensure that schools receive the resources needed to deliver assured quality education, one of the main pillars of process management that is currently not being effectively fulfilled.

Although the main focus of this study was on total effects on outcomes, it would be of interest to view direct and indirect effects in addition to investigating constructs having weak performance. The research could be extended to cover other phases of schooling starting from kindergarten, to reveal strengths and weakness in the public school system in Kuwait. Furthermore, due to the noticeable growth of private education, a similar study should be conducted to investigate the external validity of the proposed model to this important sector (grades K-12). Instruments of Employee Fulfillment focused primarily on the teaching faculty because of the key role they play in producing the school product (i.e., education) and in assuring product quality (quality education). More instruments that include all employees need be included, given the inclusive philosophy of TQM. Finally, it is recommended to launch a thorough study that investigates the satisfaction of all customers of public high school education in Kuwait.

\subsection{Conclusion}

The intent of this study was to extend the work of Anderson et al. (1994), and to test the Deming's TQM Model in an area outside of manufacturing. The vision inherent in TQM is that its concepts and philosophy are widely applicable across sectors, countries, industries, employee groups, and time periods. In that regard we believe that this study contributes to the TQM literature by investigating the applicability of Anderson's et al. (1994) quality model in public education outside of the United States of America. Also, the study extends Anderson et al. (1994) model by adding a construct (School Assured Satisfaction) before the final construct (Customer Satisfaction) in educational systems because of structural differences compared to manufacturing as was explained in detail above. The proposed modification was shown statistically to produce a valid model. Although, the study was conducted in the Kuwaiti culture, we believe this model to be externally valid and applicable in other cultures as well. We believe that this work and the application of TQM principles to education can have a transformative impact on School Assured Satisfaction and stakeholder Customer Satisfaction.

\section{References}

Al-Ghunaim M. (2013). (President of the Arab Center for Educational Research for the Gulf States,) Talk given at the "First Meeting of the Education Sector in the Ministry of Education”, Kuwait, May 282013.

Anderson, J. C., Rungtusanatham, M., \& Schroeder, R. G. (1994). A theory of quality 
management underlying the Deming management method. Academy of Management Review, 19(3), 472-509. http://dx.doi.org/10.2307/258936

Anderson, J., Rungtusanatham, M., Schroeder, R., \& Devaraj, S. (1995). A path analytic model of a theory of quality management underlying the Deming management method: Preliminary empirical findings. Decision Sciences, 26, 637-658. http://dx.doi.org/10.1111/j.1540-5915.1995.tb01444.x

Bertelsmann, \& Stiftung. (2010). ELLI: European Lifelong Learning Indicators. Making lifelong learning tangible.

Blanchard K., \& Bowles S. M. (1995). Raving fans: A revolutionary approach to customer service. New York: William Morrow and Company, Inc.

Bush, T., \& Glover, D. (2003). School leadership: Concepts and evidence. Nottingham, England: National College for School Leadership.

Cardozo R.N. (1995). An experimental study of customer effort, expectation, and satisfaction. Journal of Marketing Research, 2, 244-249. http://dx.doi.org/10.2307/3150182

Cronin J.J.J., \& Taylor, S.A. (1992). Measuring service quality: A reexamination and extension. Journal of Marketing, 56 July, 55-68. http://dx.doi.org/10.2307/1252296

Daresh, J. (2001). Supervision as proactive leadership (3rd ed.). Prospect Heights, IL: Waveland Press, Inc.

Delors, J. et al. (1996). Learning: The treasure within. Paris: UNESCO.

Douglas, T.J., \& Fredendall, L.D. (2004). Evaluating the Deming management model of total quality in services. Decision Sciences, 35(November), 393-422. http://dx.doi.org/10.1111/j.0011-7315.2004.02569.x

Evans, J. R., \& Lindsay, W. M. (2002). The Management and Control of Quality. (5th Ed.). South-Western, USA.

Feigenbaum, A.V. (1986) Total quality control (3rd. ed.). New York: McGraw-Hill.

Fisher,C.M., Barfield, J., Li, J., \& Mehta, R. (2005). Retesting a model of the Deming management method, Total Quality Management, 16(3), 401-412. http://dx.doi.org/10.1080/14783360500053758

Fitzsimmons J. A., \& Fitzsimmons M. J. (2008). Service management: Operations, strategy, information technology $\left(6^{\text {th }}\right.$ ed.). New York: McGraw-Hill

Goetsch, D.L., \& Davis, S. (1994), Introduction to Total Quality: Quality, productivity, competitiveness. New York: Macmillan College Publishing Co.

Hair, J. F. Jr., Black W. C., Babin B. J., \& Anderson R. E. (2010). Multivariate Data Analysis ( $7^{\text {th }}$ ed.). New York: Prentice Hall

Hemmen, J., Edmonson, S., \& Slate, J. R. (2009). Principals' perceptions of visionary 
leadership: A qualitative investigation. International Journal of Educational Leadership Preparation, 4(2).

Hitt, M. A., Ireland, R. D., \& Hoskisson, R. E. (2005). Strategic management: Competitiveness and globalization (6th ed.). South-Western: Business \& Economics.

IBS America, Inc., Quality 101: The 2012 Handbook for New Quality Managers 24 Hartwell Avenue. Lexington. Retrieved from www.ibs-us.com

Khan, M. A. (2009). Total Quality Management perspective of cellular mobile telephone operators in Pakistan. Doctoral Dissertation, National University of Modern Languages Islamabad, June 2009.

Lavinsky, D. (2013). Contributor Forbes 4/26/2013@ 5:05PM |9,168 views Are You a Visionary Business Leader? Retrieved from http://www.forbes.com/sites/davelavinsky/2013/04/26/are-you-a-visionary-business-lead er/

Mendez-Morse, S. (1992). Characteristics of leaders of change. Leadership Characteristics that Facilitate School Change. Retrieved April 8, 2009, from http://www.sedl.org/change/leadership/character.html

Nanus B. (1992). Visionary Leadership. Jossey-Bass Publishers: San Fransisco

Pasi, R. (2003). Introduction to the special issue: Leadership with vision and purpose. National Association of Secondary School Principals Bulletin, 87(637), 1-3. http://dx.doi.org/10.1177/019263650308763701

Pineda, A. P. M. (2013). Total Quality Management in educational institutions: Influences on customer satisfaction. Asian Journal of Management Sciences and Education, 2(3).

Rummler G. A., \& Brache, A. P. (1995). Improving performance: How to manage the white space on the organization chart ( $2^{\text {nd }}$ ed.). San Francisco: Jossey-Bass Publishers,

Rungtusanatham, M., Forza, C., Filippini, R., \& Anderson, J. (1998). A replication study of theory of quality management underlying the Deming management method: Insights from an Italian context. Journal of Operations Management, 17, 77-95. http://dx.doi.org/10.1016/S0272-6963(98)00032-1

Senge, P. (1990). The Fifth Discipline. New York: Doubleday.

Sharma, S. (1996). Applied multivariate techniques. New York: John Wiley \& Sons, Inc.

Singh R.P., G. Dhania, Sharma, A., \& Jaiwal, P. K. (2007): Biotechnological approach to improve phytoremediation efficiency for environmental contaminants. In: Environmental bioremediation technologies. (Eds.: Singh S.N., R.D. Tripathi). Springer. 223-258. http://dx.doi.org/10.1007/978-3-540-34793-4_10

Sousa, R., \& Voss, C. A. (2002). Quality management revisited: A reflective review and agenda for future research. Journal of Operations Management, 20, 91-109. 
http://dx.doi.org/10.1016/S0272-6963(01)00088-2

Spanbauer, S. J. (1995). Reactivating higher education with total quality management: Using quality and productivity concepts, techniques and tools to improve higher education. Total Quality Management, 6(5/6), 519-37. http://dx.doi.org/10.1080/09544129550035189

Tawil, S., \& Cougoureux, M. (2013). Revisiting Learning: The Treasure Within: Assessing the influence of the 1996 Delors Report. UNESCO Education Research and Foresight: UNESCO Occasional Papers.

Tribus, M. (1990). The application of quality management principles in education, at Mt. Edgecumbe High School, Sitka, Alaska. Retrieved from Quality Learning Australia www.qla.com.au

Tribus, M. (1992). TQM in education: The theory and how to put it to work. Retrieved from Quality Learning Australia www.qla.com.a

Tribus, M. (1993). Quality management in education. Retrieved from Quality Learning Australia www.qla.com.au

UNESCO. Retrieved from http://en.unesco.org/about-us/introducing-unesco

Walton, M. (1986). Deming Management Method. New York: Putnam.

Wood, M. (1997). The notion of the customer in Total Quality Management. Total Quality Management, 8(4), 181-191. http://dx.doi.org/10.1080/0954412979613

\section{Copyright Disclaimer}

Copyright for this article is retained by the author(s), with first publication rights granted to the journal.

This is an open-access article distributed under the terms and conditions of the Creative Commons Attribution license (http://creativecommons.org/licenses/by/3.0/). 